\title{
Effect of an ACTH(4-9) analogue on cisplatin neuropathy of longstanding duration: a phase II study
}

\author{
P.H.E. Hilkens ${ }^{\mathrm{a}}$, M.E..L. van der Burg ${ }^{\mathrm{b}}$, J.W.B. Moll ${ }^{\mathrm{a}}$, M.J. van den Bent ${ }^{\mathrm{a}}$, W.L.J. van Putten ${ }^{\mathrm{c}}$, \\ Ch.J. Vecht ${ }^{\mathrm{a}, *}$ \\ ${ }^{a}$ Department of Neuro-Oncology, Dr. Daniel den Hoed Cancer Center and University Hospital, P.O. Box 5201, 3008 AE Rotterdam, Netherlands \\ ${ }^{\mathrm{b}}$ Department of Medical Oncology, Dr. Daniel den Hoed Cancer Center and University Hospital, Rotterdam, Netherlands \\ 'Department of Biostatistics, Dr. Daniel den Hoed Cancer Center and University Hospital, Rotterdam, Netherlands
}

Received 27 September 1994; revised 13 January 1995; accepted 16 January 1995

\begin{abstract}
The efficacy of Org 2766, an ACTH(4-9) analogue, on the recovery of cisplatin neuropathy of longstanding duration was investigated in a phase II study. Twenty-two patients were treated with Org 2766 during a period of 4 months and vibration perception threshold (VPT) and sum scores for neuropathic symptoms and signs were compared with pre-treatment values. No change in VPT could be detected. Although there was a small improvement of clinical measures for neuropathy, no clear evidence for repair could be obtained. These results indicate no beneficial effect of Org 2766 on recovery of a longstanding cisplatin neuropathy.
\end{abstract}

Keywords: Neuropathy; Cisplatin; Vibration perception; ACTH(4-9) analogue

\section{Introduction}

Cisplatin is an effective cytotoxic agent in the treatment of various malignancies, including ovarian, testicular and bladder cancer. Since the use of vigorous hydration to reduce nephrotoxicity, peripheral neuropathy is considered the dose-limiting side effect of Cisplatin [1]. This neuropathy is characterized by a pure sensory polyneuropathy caused by damage of large myelinated fibers, possible at the level of the dorsal root ganglion [2]. Patients suffer from paresthesias, numbness, loss of tendon reflexes and a decrease in mainly thick-fiber mediated sensory qualities as vibration sense, fine touch perception and proprioception. In some patients a disabling sensory ataxia may develop [2-5]. The neuropathy may continue to deteriorate during a period of one to four months after cessation of treatment, followed by a gradual but incomplete improvement between four to twelve

*Corresponding author. Tel.: (+31-10) 439 1415; Fax: (+31-10) 4842008. months thereafter [6]. In one large prospective study the overall incidence of polyneuropathy was $47 \%$ after a median cumulative cisplatin dose of $500-600 \mathrm{mg} / \mathrm{m}^{2}$ and in only about $50 \%$ of patients, a complete recovery was observed [3].

Melanocortins, such as ACTH and melanocyte-stimulating hormone-like peptides, enhance peripheral nerve repair. The ACTH(4-9) analogue Org 2766 has demonstrated neurotrophic properties, but no corticotrophic or melanotrophic activity [7]. The ability of Org 2766 to counteract the neurotoxic side effects of cisplatin has been investigated in animal and human studies [7-12]. In a rat model it was demonstrated that Org 2766 could prevent cisplatin-induced reduction of sensory nerve conduction velocities, without compromising antitumor activity [8]. In a subsequent double-blind, placebo-controlled study in 55 patients with ovarian cancer, these results could be confirmed. Concomitant treatment with Org 2766 prevented the occurrence of neuropathy as determined by 'vibration perception threshold' (VPT) as well as for neurological signs and symptoms [9].

Presently, it is unclear whether Org 2766 can also 
improve an already established cisplatin neuropathy. One study in rats has shown that Org 2766 did not accelerate the recovery from an existing cisplatin neuropathy [10]. To address this issue in humans, we studied the effect of Org 2766 in patients with a longstanding cisplatin neuropathy of at least one year duration.

\section{Material and methods}

This study had a prospective and open design. Patients with cisplatin-induced polyneuropathy consisting of clinical symptoms and signs and an increased VPT with at least a value of $1.00 \mu \mathrm{m}$ (normal: $0.30 \pm 0.25 \mu \mathrm{m}$, mean \pm SD) and a cisplatin free interval of more than 1 year were eligible. Life expectancy had to be more than 6 months. All patients gave their informed consent. Patients with diabetes mellitus, alcohol abuse, other neurological disease and recent use of vitamin preparations were excluded. Patients enrolled in previous Org 2766 studies were also excluded from the study.

Treatment consisted of a dose of $2 \mathrm{mg}$ Org 2766 s.c. administered 3 times a week for 4 months. The severity of neuropathy was evaluated by a questionnaire for neurological symptoms, by sensory neurological testing and by assessment of VPT. Measurements were performed at the start of treatment, monthly during the first half year, every 2 months the next half year, and at 18 months after the start of treatment with Org 2766. The questionnaire enquired separately the absence (0) or presence (1) of paresthesias, numbness, loss of dexterity, unsteadiness of gait, Lhermitte sign and pain. On sensory examination various tests including position sense, vibration sense, pinprick sensation, Romberg sign, Romberg with heelto-toe stand and tight rope walking were scored as normal (0) or abnormal (1). A sum score for these symptoms and signs was calculated $(\min 0, \max 12)$. Two-point discrimination on the dorsal hand (interval 1.5, 3, 5 and $10 \mathrm{~cm}$ ) and on the distal tibia (interval 4 and $10 \mathrm{~cm}$ ) was measured, and scored as normal (0) or abnormal (1) per interval. A discrimination-sense score was calculated ( $\min 0, \max 6$ ). VPT was measured at the dorsum of the second metacarpal bone of the left hand with a Vibrame-

Table 1

Vibration perception threshold (VPT in $\mu \mathrm{m}$ ), sum score and discrimination-sense score in patients treated with Org 2766 . Values are mean $( \pm \mathrm{SD})$.

\begin{tabular}{lllll}
\hline $\begin{array}{l}\text { Months since } \\
\text { start treatment }\end{array}$ & $n$ & VPT $^{\text {a }}$ & Sum score & $\begin{array}{l}\text { Discrimination- } \\
\text { sense score }\end{array}$ \\
\hline 0 & 22 & $3.1( \pm 2.8)$ & $6.8( \pm 2.7)$ & $3.3( \pm 1.5)$ \\
6 & 22 & $2.7( \pm 2.5)$ & $7.2( \pm 2.0)$ & $2.4( \pm 1.0)$ \\
12 & 14 & $2.6( \pm 2.7)$ & $6.4( \pm 2.6)$ & $2.1( \pm 1.3)$ \\
18 & 14 & $3.3( \pm 2.4)$ & $6.1( \pm 2.1)$ & $2.1( \pm 0.9)$ \\
\hline
\end{tabular}

${ }^{2} 4$ patients with pretreatment VPT regarded as outliers are excluded from calculation. ter type III (Somedic AB, Stockholm, Sweden) and recorded in $\mu \mathrm{m}$ of skin displacement. The Vibrameter uses a vibratory frequency of $100 \mathrm{~Hz}$ and corrects for pressure-induced alterations in vibratory amplitude. The method of limits was used to obtain the mean VPT which was repeated 3 times. This method has been shown to be sensitive and reproducible [13].

On average eight complete evaluations were obtained per patient. Linear regression analysis was applied by which for each patient the natural logarithm of VPT, the sum score and the discrimination-sense score were fitted against time. From the fitted lines the change over a period of one year for each of these three parameters was calculated. These values were used to calculate Spearman rank correlation coefficients between these parameters and to test whether any of these changes were statistically significantly different from 0 , using the Wilcoxon signed rank test.

\section{Results}

A total of 22 patients ( 7 males, 15 females) were entered into the study. The mean age was 57 years (range 32-74 years). Primary tumor was ovarian cancer in 15, melanoma in 1, and testicular cancer in 6 patients. The median cumulative cisplatin dose patients had received was $575 \mathrm{mg} / \mathrm{m}^{2}$ (range $375-900 \mathrm{mg} / \mathrm{m}^{2}$ ). The median time interval between the last cisplatin administration and start of therapy was 4 years (range 1-9 years). Fourteen patients had been treated by combination chemotherapy, 9 including hexamethylmelamine (median dose 15.7 $\mathrm{g} / \mathrm{m}^{2}$, range 9.8-45.6), 3 including vincristine $(6,12$ and $\left.14 \mathrm{mg} / \mathrm{m}^{2}\right)$ and 2 including vinblastine $\left(80\right.$ and $\left.90 \mathrm{mg} / \mathrm{m}^{2}\right)$. All 22 patients could be followed until 6 months and 14 patients until 18 months after treatment. Three patients reported a subjective improvement and one patient a deterioration of symptoms after 6 months of treatment. One patient had stopped therapy with Org 2766 after 2 months for psychological reasons. No adverse effects of Org 2766 were observed.

Table 1 shows the mean VPT, mean sum score and mean discrimination-sense score before start of treatment and during follow up. Four patients showed extremely high VPT values before treatment with substantially lower values at subsequent measurements, which

Table 2

One-year change in log VPT, sum score and discrimination sense-score ${ }^{\mathrm{a}}$

\begin{tabular}{lll}
\hline & Mean $( \pm \mathrm{SD})$ & $p$ value \\
\hline $\log$ VPT & $-0.02( \pm 0.47)^{\mathrm{b}}$ & 0.41 \\
Sum score & $-0.90( \pm 1.76)$ & 0.046 \\
Discrimination-sense score & $-1.11( \pm 1.06)$ & 0.0004 \\
\hline
\end{tabular}

${ }^{a}$ Calculated from linear regressions.

${ }^{b}$ Equivalent to a relative decrease in VPT of $8 \%$. 
were not accompanied by similar changes in the sum score and discrimination-sense score. These 4 pretreatment VPT values were regarded as outliers and excluded from the calculations of the mean VPT and 1-year change in log VPT.

Table 2 shows the mean values for the fitted one-year change in log VPT, sum score and discrimination-sense score. It shows a statistically significant decrease of approximately 1 point for both sum score and discrimination-sense score. There was no significant decrease in VPT. Furthermore, there was no evidence of a clear positive association between the 1-year changes of these parameters (Spearman rank correlations between -0.22 and +0.16 ).

\section{Discussion}

The results of the present study indicate no clear beneficial effect of Org 2766 on a cisplatin-induced neuropathy of 1 year duration or more. Gerritsen van der Hoop et al. [9] showed that Org 2766, when given concomitantly with cisplatin, can prevent or attenuate an increase in VPT and sum score for neuropathic symptoms and signs. The same measurernents were used in the present study, together with a score for discrimination-sense which was added as a third neuropathy-parameter. The VPT has been demonstrated to be a reliable and quantitatively valid indicator of cisplatin neuropathy $[4,14]$. The VPT did not show a significant decrease following treatment with Org 2766. Both the sum score for symptoms and signs and the discrimination-sense score showed some improvement which however was so small, that we would consider this clinically irrelevant.

These results are in agreement with a previous study in a rat model that could not demonstrate acceleration of recovery of an existing cisplatin neuropathy by Org 2766 [10]. It has been suggested that melanocortins, such as Org 2766 , mimic or amplify an endogenous signal that operates in the regenerative response of the damaged nerve. Observations in arimal studies that Org 2766 is only active in the early phase of nerve regeneration, may explain the failure of this peptide to enhance recovery in longstanding cisplatin neuropathy $[7,11]$. After about 8 days following nerve injury no further effect on regeneration could be detected in the rat [7]. Apparently, enhancement of nerve repair by Org 2766 seems to be limited to a critical early period after nerve damage.

We conclude that this study indicates no efficacy of Org 2766 on the recovery of a longstanding cisplatininduced neuropathy. In the prevention of cisplatin neuropathy, Org 2766 seems beneficial only when administered concomitantly with cisplatin.

\section{References}

[1] Hamers, F.P.T., Gispen, W.H. and Neijt, J.P. (1991) Neurotoxic side-effects of cisplatin. Eur. J. Cancer, 27: 372-376.

[2] Thompson, S.W.E., Davis, L.E., Kornfeld, M., Hilgers, R.D. and Standefer, J.C. (1984) Cisplatin neuropathy: clinical, electrophysiologic, morphologic, and toxicologic studies. Cancer, 54: 12691275 .

[3] Gerritsen van der Hoop, R., Van der Burg, M.E.L., Ten Bokkel Huinink, W.W., Van Houwelingen, J.C. and Neijt, J.P. (1990) Incidence of neuropathy in 395 patients with ovarian cancer treated with or without cisplatin. Cancer, 66: 1697-1702.

[4] Roelofs, R.I., Hrushesky, W., Rogin, J. and Rosenberg, L. (1984) Peripheral sensory neuropathy and cisplatin chemotherapy. Neurology, 34: 934938.

[5] Vecht, C.J., Hovestadt, A., Verbiest, H.B.C., Van Putten, W.L.J., Neijt, J.P.and Van der Burg, M.E.L. (1991) Org 2766 in the prevention of cisplatin neuropathy. In: Howell,S.B., (Ed.), Platinum and Other Metal Coordination Compounds in Cancer Chemotherapy, Plenum press, New York, NY, pp. 501-508.

[6] Hovestadt, A., Van der Burg, M.E.L., Verbiest, H.B.C., Van Putten, W.L.J. and Vecht, C.J. (1992) The course of neuropathy after cessation of cisplatin treatment, combined with org 2766 or placebo. J. Neurol., 239: 143-146.

[7] De Koning, P. and Gispen, W.H. (1987) Org.2766 improves functional and electrophysiological aspects of regenerating sciatic nerve in the rat. Peptides, 8: 415-422.

[8] Gerritsen van der Hoop, R., De Koning, P., Boven, E., Neijt, J.P., Jennekens, F.G.I. and Gispen, W.H. (1988) Efficacy of the neuropeptide org 2766 in the prevention and treatment of cisplatininduced neurotoxicity in rats. Eur. J. Cancer Clin. Oncol., 24: 637-642.

[9] Gerritsen van der Hoop, R., Vecht, C.J., Van der Burg, M.E.L., Elderson, A., Boogerd, W., Heimans, J.J., Vries, E.P., Van Houwelingen, J.C., Jennekens, F.G.I., Gispen, W.H. and Neijt, J.P. (1990) Prevention of cisplatin neurotoxicity with an ACTH(4 9) analogue in patients with ovarian cancer. New Engl. J. Med., 322: 89-94.

[10] Hamers, F.P.T., Pette, C., Bravenboer, B., Vecht, C.J., Neijt, J.P. and Gispen, W.H. (1993) Cisplatin-induced neuropathy in mature rats: effects of melanocortin-derived peptide Org 2766. Cancer Chemother. Pharmacol., 32: 162-166.

[11] Verhaagen, J., Edwards, P.M., Jennekens, F.G.I., Schotman, P. and Gispen, W.H. (1987) Early effects of an ACTH(4-9) analog (org 2766) on regenerative sprouting demonstrated by the use of neurofilament binding antibodies isolated from a serum raised by $\alpha$-MSH immunization. Brain Res., 404: 142-150.

[12] Van Gerven, J.M.A., Hovestadt, A., Moll, J.W.B., Rodenburg, C.J., Splinter, T.A.W., Van Oosterom, A.T., Keizer, L., Drogendijk, T.E., Groenhout, C.M., Vecht, Ch.J. and Neijt, J.P. (1994) The effect of an ACTH(4-9) analogue on development of cisplatin neuropathy in testicular cancer: a randomized trial. J. Neurol., 241: 432-435.

[13] Goldberg, J.M. and Lindblom, U. (1979) Standardised method of determining vibratory perception thresholds for diagnosis and screening in neurological investigation. J. Neurol. Neurosurg. Psychiat., 42: 793-803.

[14] Elderson, A., Gerritsen van der Hoop, R., Haanstra, W., Neijt, J.P., Gispen, W.H. and Jennekens, F.G.I. (1989) Vibration perception and thermoperception as quantitative measurements in the monitoring of cisplatin induced neurotoxicity. J. Neurol. Sci., 93: $167-174$ 